\title{
Comparative evaluation for the adsorption of toxic heavy metals on to millet, corn and rice husks as adsorbents
}

\begin{abstract}
This study was carried out to evaluate the efficiency of metals ( $\mathrm{Ni}, \mathrm{Cr}$, and $\mathrm{Mn}$ ) removal using, raw and carbonized rice, millet and corn husks as low cost adsorbents. The sorption of these metal ions from aqueous solution was determined using Atomic Absorption Spectroscopy Analysis (AAS). Characterisation of the adsorbents using Fourier Transform Infra Red) FTIR) and Scan Electron Microscopy (SEM) images revealed some changes before and after the adsorption process. This indicated that, most likely adsorption has been taken place between the metal ions and the adsorbents in the aqueous solution. Batch experiments were carried out to determine the effect of different parameters such as adsorbent dose, $\mathrm{pH}$ of the medium, contact time and agitation rate. The result obtained showed that the sorption process was largely dependent on metal ion concentration, adsorbent dose and contact time. The experimental data was analyzed using paired sample $-\mathrm{T}$ test. The study also showed that, all the husks were effective for the quantitative removal of various toxic heavy metals and can be used as low cost and highly efficient adsorbents for the removal of heavy metal ions from industrial effluents.
\end{abstract}

Keywords: corn husk, millet husk, rice husk, batch adsorption, toxic heavy metals, carbonised
Volume 8 Issue 3 - 2019

\author{
Samaila Muazu Batagarawa, Alayande Kehinde \\ Ajibola \\ Department of Pure and Industrial Chemistry, Umaru Musa \\ Yar'adua University Katsina, Nigeria
}

Correspondence: Samaila Muazu Batagarawa, Department of Pure and Industrial Chemistry, Umaru Musa Yar'adua University Katsina, Nigeria, Email samaila.muazu@umyu.edu.ng

Received: April 14, 2019| Published: May 24, 2019

\section{Introduction}

Recently, a great deal of interest in the research for the removal of heavy metals from industrial effluents has focused on the use of agricultural by-products as adsorbents. The use of agricultural by products in bio-remediation of heavy metal ions, which is known as bio-sorption, is an aspect of Bio-technology. This is recognized as an emerging technique for the treatment of heavy metal polluted streams. ${ }^{1}$ The bio-sorption offers an alternative to remediation of industrial effluents as well as the recovery of metals contained in other media. $^{2}$ According to World Health Organization ${ }^{3}$ the metals of most immediate concern are $\mathrm{Cr}$ III, Cr (VI), Zn, Cd, Cu. Ni, Hg, Pb, Al, Mn. ${ }^{4}$ Conventional methods for heavy metals removal from industrial waste water include reverse osmosis, electromechanical reduction, chemical precipitation, ion exchange, ${ }^{5}$ membrane filtration and coprecipitation. ${ }^{6}$ Most of these methods suffer from drawn backs as high capital and operational cost which are not suitable for small scale industries. ${ }^{7,8}$ The adsorption capacity of agricultural waste biomass varies significantly. Factors that influence the removal of heavy metals by agricultural waste biomass include types of crop residues, elements of heavy metals, pre-treatment of agricultural waste biomass and operating conditions. ${ }^{9}$ An important characteristics of good adsorbents is their high porosity and consequent large surface area with more specific adsorption, it also increases the adsorption kinetic. A better adsorbent is the one with large surface area which requires less time for adsorption. About $40 \%$ of the weight of the harvested millet is removed as husk from the stalk. The husk is sometimes used as landfills or animal feeds. It is also found as heaps of unused wastes which are sometimes burn to ashes, thus giving rise to environmental pollution. ${ }^{10}$ The Northern part of the country is known for the large scale farming of rice, corn and millet. The husk of these materials can be used as adsorbents if processed instead of causing environmental pollution if using otherwise or not making use of it at all.
Rudre et al., ${ }^{11}$ performed an experiment using millet husk as an adsorbent to remove cu (II) from electroplating effluent. Batch experiment was conducted at temperature $28^{\circ} \mathrm{C}$ to determine parameters such as contact time, adsorbent dosage, $\mathrm{pH}$ and initial concentration. The maximum removal efficiency of cu(II) was 86.86 $\%$ for $1.0 \mathrm{~g} / 50 \mathrm{ml}$ of millet husk at $\mathrm{pH} 2.0$ and equilibrium contact time of 4 hours with the initial concentration of $6.24 \mathrm{mg} / \mathrm{l}$. It was concluded that millet husk has high potential adsorption of $\mathrm{Cu}$ (II) removal. The purpose of the research is to assess the potentials of using rice husk, millet husk and maize cob as adsorbents to remove some toxic heavy metals from aqueous solution.

\section{Materials and methods}

\section{Sample collection}

The rice husk was collected from Funtua rice mill, while the corn and millet husks were collected at a local mill in Batagarawa Local Government, Katsina State. All the samples were collected in a polythene bag, labelled appropriately and brought to the laboratory for further analysis.

\section{Sample treatment}

The samples were washed with tap water several times to remove adhering particles. They were dried in the air for 24 hours and soaked in $1 \mathrm{M}$ dilute $\mathrm{HCl}$ at room temperature. They were filtered and washed several times with tap water and finally with distilled water until fairly constant $\mathrm{pH}$ were obtained. The samples were dried in the oven at $100{ }^{\circ} \mathrm{C}$ for 24 hours. The dried husks were treated according to the methods. ${ }^{12-14}$

Each of the three husks was divided into two portions. The first portion was carbonized in the murfle furnace at $500^{\circ} \mathrm{C}$ for 6 hours, while the second portion was grinded with pestle and mortar and sieved using $300 \mu \mathrm{m}$ sieve and stored in plastic container. The samples 
were labeled as Carbonized Corn Husk $(\mathrm{CCH})$, Uncarbonized Corn Husk (UCH), Carbonized Millet Husk (CMH), Uncarbonized Millet Husk (UMH), Carbonized Rice Husk (CRH) and Uncarbonized Rice Husk (URH).

\section{Batch adsorption experiments}

Adsorption experiments were carried out using batch adsorption method. Various parameters such as metal ion concentrations, contact time, adsorbent dosage and $\mathrm{pH}$ of the solution were studied at constant agitation rate of $200 \mathrm{rpm}$, and room temperature of $25^{\circ} \mathrm{C}$ for each adsorption experiment. $50 \mathrm{ml}$ aqueous solution of each metal ion was equilibrated with varying sorbent dosage $(0.2-0.6 \mathrm{~g})$, contact time (20-40min). The $\mathrm{pH}$ was adjusted to $2-10$ and agitation rate of $(100$ 300rpm). The experiments were performed using on Orbital Shaker (Scigenics Biotech Orbitek). The results were calculated based on the formular;

$$
\begin{aligned}
& \% \text { removal }=\frac{C o-C e}{C o} \times 100--------3.2 \\
& q e=\frac{(C o-C e) V}{w}----------3.3
\end{aligned}
$$

Where $\mathrm{Co}$ and $\mathrm{Ce}$ are the concentrations $(\mathrm{mg} / \mathrm{L})$ of metal Ions initially and at equilibrium time $\mathrm{W}$ is the weight of the adsorbed (mg), qe is the amount of metal ion adsorbed $(\mathrm{mg} / \mathrm{g})$, while $\mathrm{V}$ is the volume of the solution in litre. ${ }^{15-17}$

\section{Reusability of the adsorbents}

The reusability was done by making use of the used adsorbents, they were soaked in $50 \mathrm{ml} 0.1 \mathrm{M} \mathrm{HCl}$ for $2 \mathrm{hrs}$. It was filtered and rinsed in deionised water several times to remove the excess acid. It was reused by treating it with $50 \mathrm{ml}$ of the aqueous solution for a predetermined time and agitated rate. The filtered sample was analyzed using AAS The reusability experiment was carried out on each of the adsorbents for the second time and the filtrate was analyzed using AAS. The procedure used was similar to that of Batagarawa and Lawal. ${ }^{18}$

\section{Determination of specific surface area}

The specific surface of the Adsorbents was estimated using Sear's method, ${ }^{19}$ by agitating $1.5 \mathrm{~g}$ of the adsorbent sample for each in $100 \mathrm{ml}$ of diluted hydrochloric acid of $\mathrm{pH}=3$. Then $30 \mathrm{~g}$ of Sodium Chloride was added with stirring and the volume was made up of $150 \mathrm{ml}$ with deionized water. The solution was titrated with $0.1 \mathrm{M} \mathrm{NaOH}$ and the volume, $\mathrm{v}$ needed to raise the $\mathrm{pH}$ from 4-9 was then recorded. The surface area according to this method was calculated using the following equation.

$$
S\left(m^{2} g^{-1}\right)=32 V-25
$$

\section{Scanning Electron Microscopy (SEM)}

The Scanning Electron Microscopy (SEM) experiment was carried out on the adsorbent using Philip XL 30 at accelerating voltage of 10 $\mathrm{KV}$, beam size 3.0 and of different magnifications. The micrographs before and after the adsorption of metal ions and compared to study the adsorption efficiency of the adsorbent.

\section{Statistical analysis}

The analysis of the data was done using paired sample T-test This was done to compare the means of the samples before and after adsorption. The data was presented using tables and bar charts. The statistical softwares used were Microsoft excel and SPSS.

\section{Results and discussion}

\section{Effect of metal ion concentration}

The effects of initial metal ion concentration on the adsorption efficiency of the adsorbents are shown in Figures 1(A-C). The result shows that as the initial metal ion concentration for chromium increases, the percentage removal efficiency increased for the six adsorbents (Figure 1A). The percentage removal follows the order; $99.6 \%$ for $\mathrm{CRH}>99.5 \%$ for $\mathrm{URH}>98.9 \%$ for $\mathrm{CCH}>98.7 \%$ for $\mathrm{CMH}$ $98.6 \%$ for $\mathrm{UCH}$ and $98.5 \%$ for $\mathrm{UMH}$. The percentage removal of nickel ions from aqueous solution using the six adsorbents attained equilibrium at $1 \mathrm{mg} / \mathrm{L}$ is shown in Figure $1 \mathrm{~B}$. The optimum removal efficiency for Nickel follows the oder; $98.9 \%$ for CRH $>98.8 \%$ for $\mathrm{CMH}>98.7 \% \mathrm{URH}>98.5 \%$ for $\mathrm{CCH}>97.5 \%$ for $\mathrm{UMH}$ and $97.0 \%$ for $\mathrm{UCH}$.

Similar trend as above was observed in the adsorption of $\mathrm{Mn}(\mathrm{II})$ ions as shown in Figure 1C; with $99.3 \%$ for CRH and $98.5 \%$ for URH both for Rice husks. The result is in accordance with the report of Okeimen and Onyekpa. ${ }^{20}$

\section{Effect of adsorbent dosage}

The availability and accessibility of adsorption site is controlled by adsorbent dosage. ${ }^{21}$ The effect of mass of adsorbent loading on heavy metal removal were investigated by varying adsorbent loading from 0.2 to $0.8 \mathrm{~g}$ per $50 \mathrm{ml}$ of mixed metal Ion solutions. From Figures $2(A-C)$, it can easily be inferred that the percentage removal of metal ions increased with increasing weight of adsorbent. This could be due to the greater availability of the exchangeable sites or surface area at higher dose.

The removal efficiency for chromium varies for $\mathrm{CCH}$ from $96.5 \%$ to $98.8 \%$ for $\mathrm{UCH} 98.0 \%$ to $99.0 \%$, $\mathrm{CMH}$ from $95.8 \%$ to $98.1 \%$, UMH from $83.1 \%$ to $94.7 \%$, CRH from $93.3 \%$ to $99.5 \%$ and URH from $92.1 \%$ to $99.8 \%$. For manganese ion, the removal efficiency varies for $\mathrm{CCH}$ from $91.0 \%$ to $97.6 \%$, for $\mathrm{UCH}$ from $92.1 \%$ to $97.9 \%$, for $\mathrm{CMH}$ from $90.0 \%$ to $98.1 \%$ for UMH from $95.1 \%$ to $98.5 \%$, for CRH from $94.0 \%$ to $99.5 \%$ and for URH from $93.5 \%$ to $99.3 \%$.

\section{Effect of agitation rate}

The effect of agitation rate was studied by using the agitation rate of $100 \mathrm{rpm}, 200 \mathrm{rpm}$ and $300 \mathrm{rpm}$ respectively, keeping all other factors constant, that is using concentration of $1.0 \mathrm{mg} / 1$ and contact time of $60 \mathrm{~min}$ for the adsorption of chromium, Nickel ion and Manganese using six different adsorbents. At 200rpm, the adsorption of the metal reached maximum for all the three metals using $\mathrm{CCH}, \mathrm{UCH}, \mathrm{CMH}$, $\mathrm{UMH}, \mathrm{CRH}$ and URH as adsorbents as shown in Figures 3(A-C). This is due to the attractive between the metal and adsorption site of the Adsorbents. At the higher agitation rate, the molecule of the metals do not have enough time for contact with the active sites of the adsorbents, because the rate of agitation is very fast. Increasing the agitation rate at moderate level enhance the metal ion diffusion to the surface of the adsorbents and also causes adsorption in the film boundary layer around the adsorbents, thereby leading to an increase in adsorption. Decrease in percentage of metal ions adsorbed as the rate of agitation increase could be as a result of desorption of some metal Ions from the surface of the adsorbent due to too vigorous agitation rate.

\section{Effect of contact time}

The effect of contact time on the adsorption efficiency was shown in Figures $4(\mathrm{~A}-\mathrm{C})$. Adsorption experiments were carried out at 
different time intervals; 20, 30 and 40 min in mixed metal Ions. It was observed that the removal of tested metal was rapidly achieved within a short period of $20 \mathrm{~min}$. Adsorption of chromium and nickel Ions attained maximum within $20 \mathrm{~min}$ while that of manganese within $30 \mathrm{~min}$. previous results by some researchers revealed that removal of all tested metal was rapidly removed within a period of $30 \mathrm{~min} .{ }^{22}$ The effect of contact time on adsorption process of metal Ions from waste waters were studied by many authors. ${ }^{23-26}$ The result indicated that the equilibrium time was dependent on the nature of the adsorbent and on metal Ions concentration.
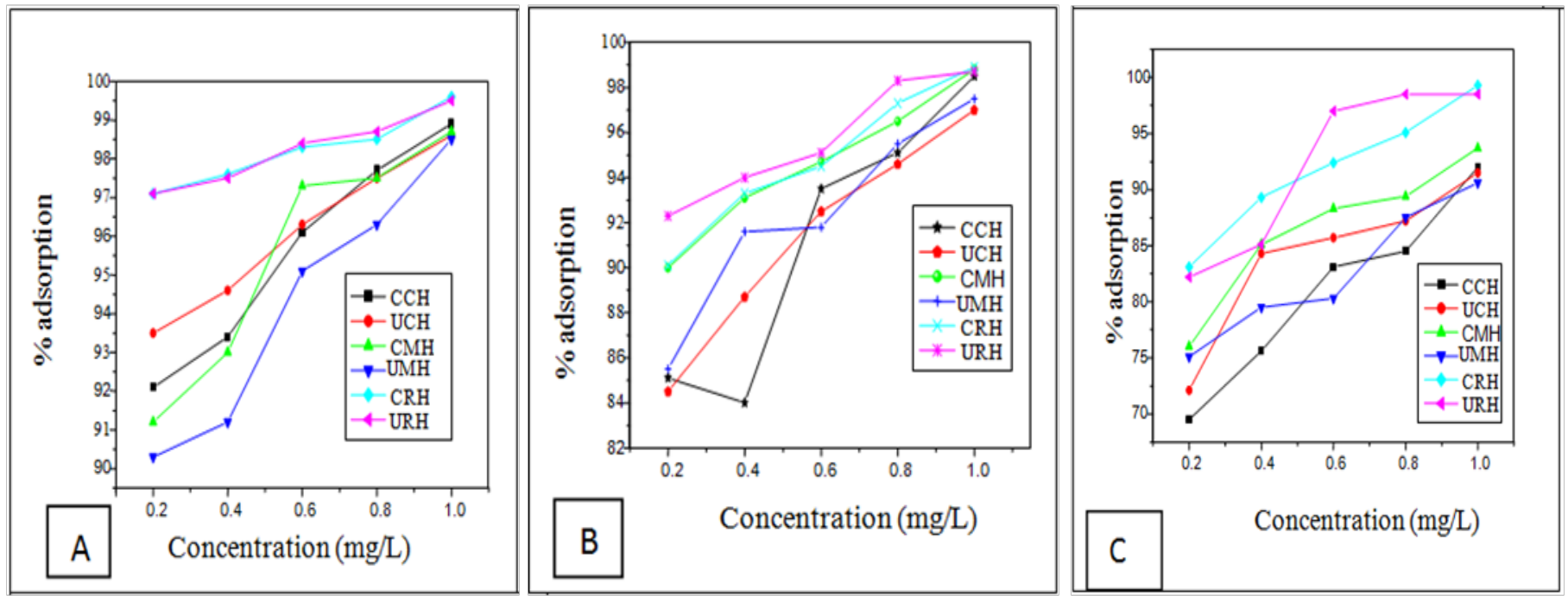

Figure I Effect of Metal ion Concentration on Removal of (A) Chromiun (B) Nickel and (C) Manganese removal.
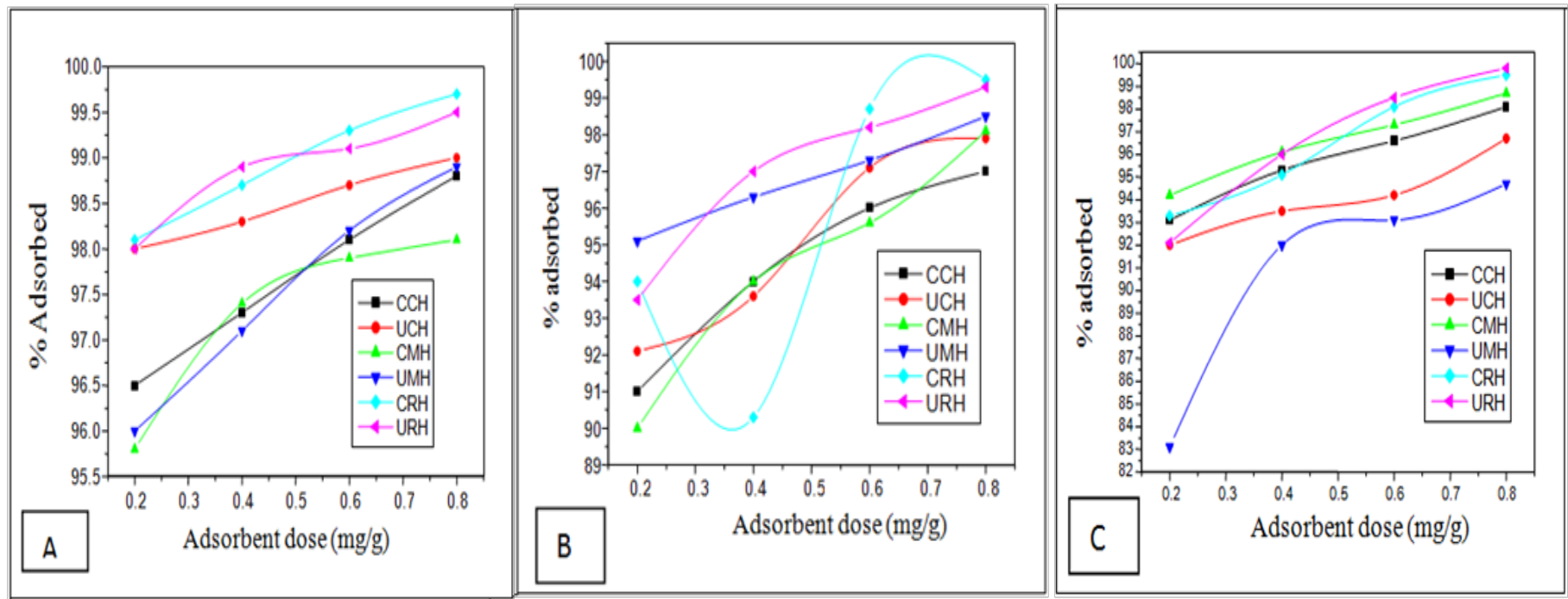

Figure 2 Effect of adsorbent dosage on (A) Chromium (B) Nickel and (C) Manganese removal.

\section{Effect of $\mathrm{pH}$}

The $\mathrm{pH}$ adsorption for $\mathrm{Cr}$, $\mathrm{Ni}$ and $\mathrm{Mn}$ are shown in Figures 5(A-C) respectively. All the experiments were carried out in the $\mathrm{pH}$ values of 2, 6 and 10, where chemical precipitation is almost avoided, so that metal removal could be related to the adsorption process. ${ }^{27}$ The susceptibility of the system $\mathrm{pH}$ changes may be attributed to the nature of the ions in solution and the nature of the adsorbent used. The lower the $\mathrm{pH}$, the more the $\mathrm{H}^{+}$ions competing with the metal ions for adsorption sites, thus reduces their adsorption. On the other hand, the higher the $\mathrm{pH}$ the less the $\mathrm{H}^{+}$ions competing with metal ions for adsorption sites, thus increasing their adsorption.
The maximum adsorption of $\mathrm{Ni}$ and $\mathrm{Mn}$ occurred at $\mathrm{pH}$ 6.0, which was similar to the result obtained for the adsorption of $\mathrm{Cd}(\mathrm{II})$ ions by coconut copra meal. ${ }^{28,29}$

Chromium ions are available as $\mathrm{CrO}_{3}{ }^{2-}$ or $\mathrm{HCrO}_{3}{ }^{-}$in the solution. It has been found that bio sorption of chromium decreases with increases in the $\mathrm{pH}$ of the solution. Possible reason may be the presence of more number of sites on the bio sorbent at lower $\mathrm{pH}$ which can absorb chromate ions. At high $\mathrm{pH}$, precipitation usually occurred between metal ions and hydroxide ions. ${ }^{28}$ 

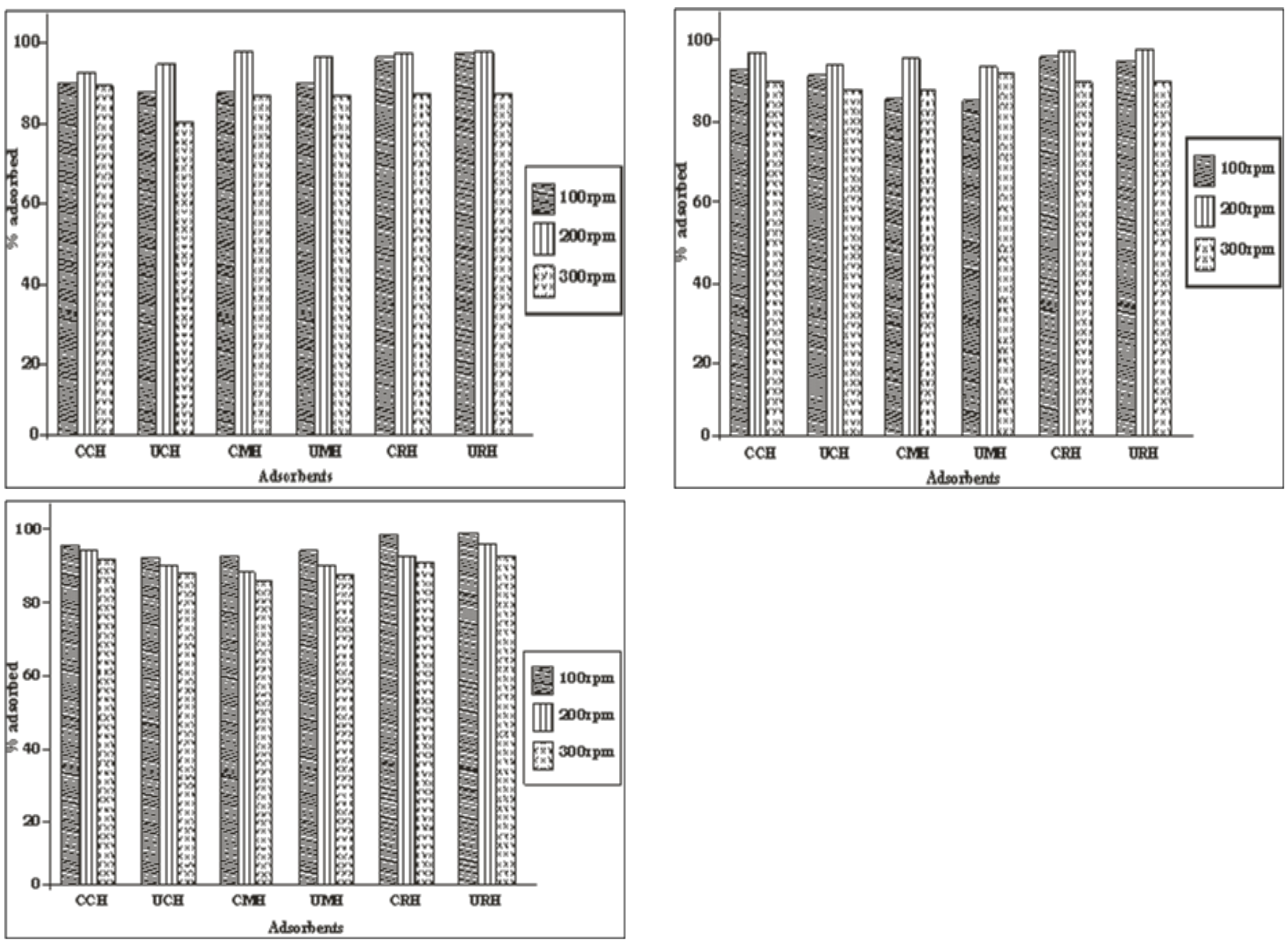

Figure 3 Effect of agitation rate on (A) Chromium (B) Nickel and (C) Manganese removal.
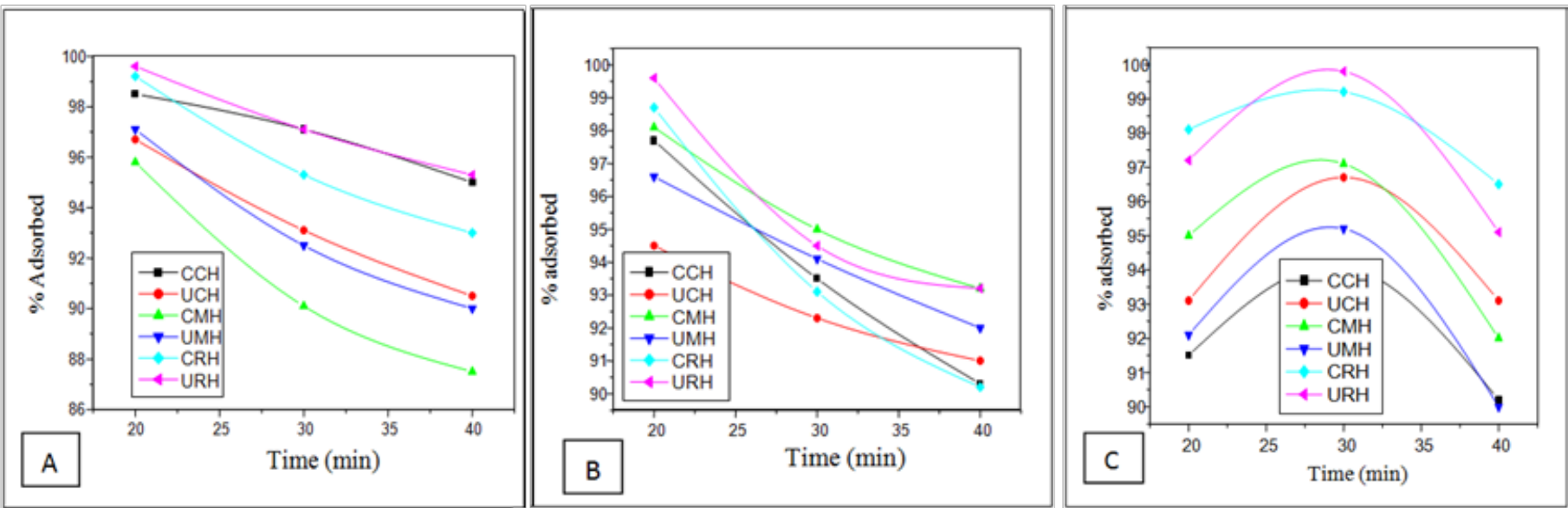

Figure 4 Effect of contact time on (A) Chromium (B) Nickel and (C) Manganese removal.

\section{Surface area analysis}

The Sear's Specific Surface Area of the adsorbents samples is presented in Table 1. It has been reported that a single gram of adulterated carbon can have a surface area in excess of $500\left(\mathrm{~m}^{2} \mathrm{~g}^{-1}\right)$, with $1500 \mathrm{~m}^{2} \mathrm{~g}^{-1}$ being readily achievable. Therefore $\mathrm{CCH}, \mathrm{UCH}$
$\mathrm{CMH}, \mathrm{UMH}, \mathrm{CRH}$ and URH having specific surface area of $524 \mathrm{~m}^{2} \mathrm{~g}$ ${ }^{1}, 519 \mathrm{~m}^{2} \mathrm{~g}^{-1}, 527 \mathrm{~m}^{2} \mathrm{~g}^{-1}, 520 \mathrm{~m}^{2} \mathrm{~g}^{-1}, 537 \mathrm{~m}^{2} \mathrm{~g}^{-1}$ and $531 \mathrm{~m}^{2} \mathrm{~g}^{-1}$ respectively and therefore were in agreement with the literature. And we can see from the table that all the adsorbents have good surface area that allowed them adsorbed effectively, but CRH, with highest surface area adsorbed more than others. 

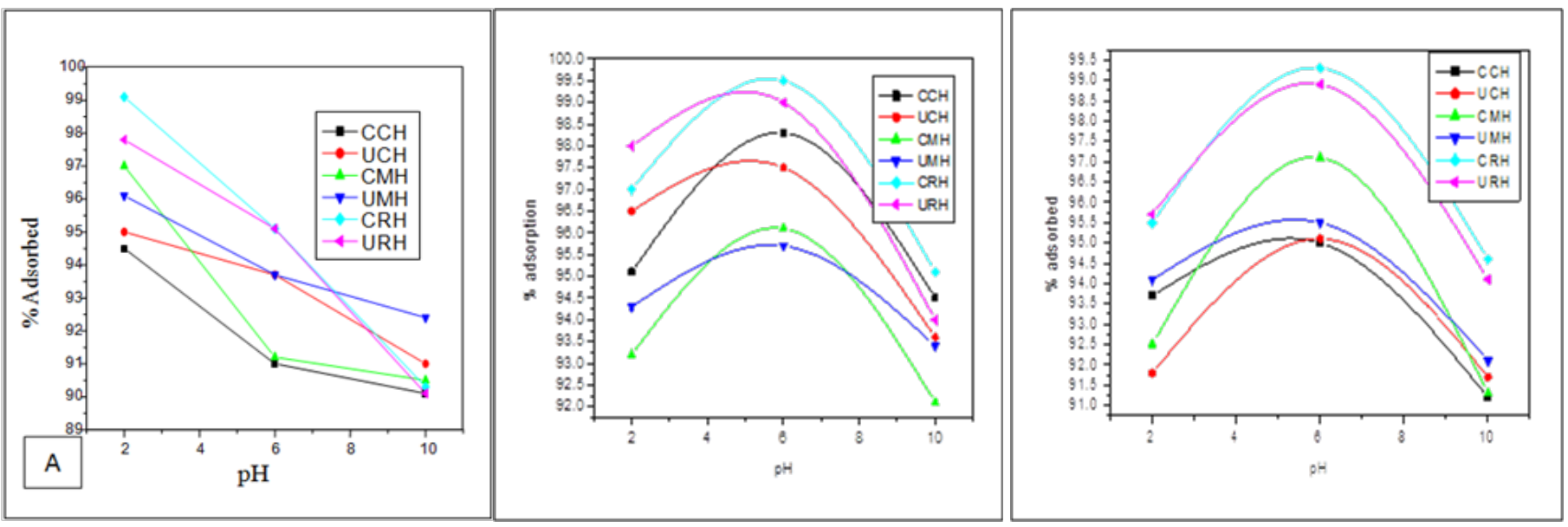

Figure 5 Effect of $\mathrm{pH}$ on (A) Chromium (B) Nickel and (C) Manganese removal.

Table I The surface area of the various adsorbents

\begin{tabular}{lllllll}
\hline & CCH & UCH & CMH & UMH & CRH & URH \\
\hline Sear's specific surface area $\left(\mathrm{m}^{2} \mathrm{~g}^{-1}\right)$ & 524 & 519 & 527 & 520 & 537 & 531 \\
\hline
\end{tabular}

\section{Fourier Transform Infrared (FT-IR) Spectroscopy}

FTIR technique is an important tool to identify some characteristics functional groups, which are capable of adsorbing metal ions and at the same time instrumental in adsorption process. The most important constituent of agricultural waste are carbohydrates, therefore the functional groups of choice are $\mathrm{C}=\mathrm{O}$ and $\mathrm{OH}$ (Figure 6).

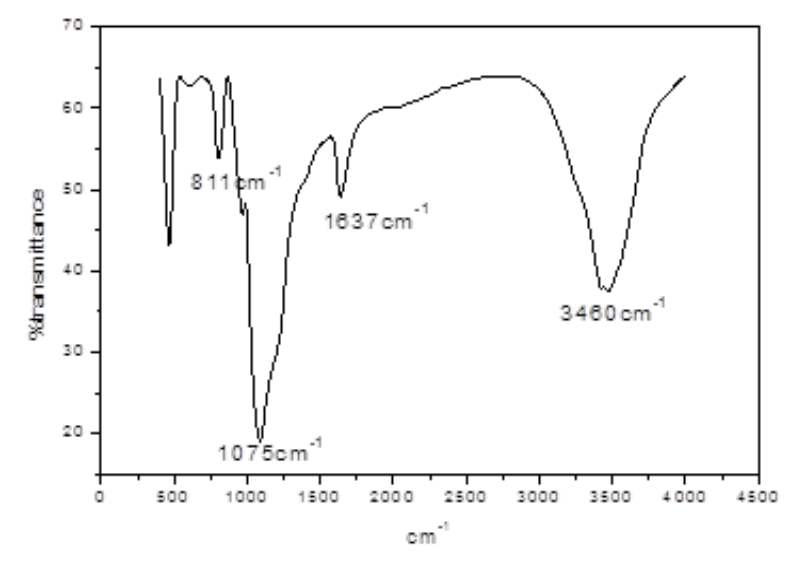

Figure 6 FTR spectra of uncarbonised millet husk.

The FT IR graph showed a strong intensity band at $3460 \mathrm{~cm}^{-1}$, which is associated with $\mathrm{OH}$ from water and other carbohydrates present. The spectra also shows a band at $1637 \mathrm{~cm}^{-1}$, which is attributed to the presence of Carbonyl $(\mathrm{C}=\mathrm{O})$ from cellulose, in addition to a strong absorption at $1075 \mathrm{~cm}^{-1}$ which is due to Si-O-Si vibration.

\section{Scanning Electron Microscopy (SEM)}

Scanning Election Microscopy (SEM) has been extensively used to characterize the microstructure of carbonized corn husks before and after adsorption. The morphological study of the micrographs for carbonised and uncarbonised husks is shown in plates 1 and 2 respectively. The SEM in plate 1 showed partially developed honey comb-like and highly defined pores. It shows that, carbonization influenced the topographical characteristics of the adsorbents. Plate 2 shows the surface structure after adsorption of Nickel metal from aqueous solution. The image revealed that the external surface consist of small cavities, characterized by irregular heterogeneous surface which suggested presence of adsorbed metal ions on the surface. Before metal uptake for both carbonized and uncarbonized corn husks, the images revealed that the external surface was full of cavities, roughly characterized by irregular heterogeneous surface which suggested that, uncarbonised corn husk exhibit high surface area, however, the carbonized corn husk has more distinguish pores than that of uncarbonized corn cob, indicating that it will have more surface area than uncarbonized corn cob, and large surface area increased the rate of adsorption. Absence of some pores and lighter surface of the adsorbents after metal ion adsorption suggested that, metal ions adsorption had taken place (Figure 7).

\section{Statistical analysis}

To have an insight into the effectiveness of $\mathrm{CCH}, \mathrm{UCH}, \mathrm{CMH}$, $\mathrm{UMH}, \mathrm{CRH}$ and URH in the removal of heavy metal ions from aqueous solutions, paired sample t-test analysis was carried out on the results. Paired sample t-test analysis was used to find out the level of significance between two values. The initial concentration of the metal ions in the aqueous solution was compared to the final concentration after metal ion adsorption to see if there is a level of significance in the amount of metal ion adsorbent. The significance level determines the effectiveness of the adsorbents in the removal of heavy metals from waste water sample. The adsorbents are effective in the removal of heavy metals from waste samples if the level of significance is less than 0.05 .

The removal of chromium ions gave the following level of significance; $0.013,0.014,0.013,0.014$ and 0.014 , while Nickel 
ions have the following values; $0.014,0.014,0.014,0.014,0.016$ and 0.013 . Manganese ions showed the following level significance of removal; $0.014,0.014,0.014,0.014,0.014$, and 0.021. From the results obtained, it can be observed that, significant level of less than 0.05 was obtained for all the four adsorbents. It can therefore be concluded that the adsorbents were very effective in the removal of Chromium, Nickel and Manganese from aqueous solutions.
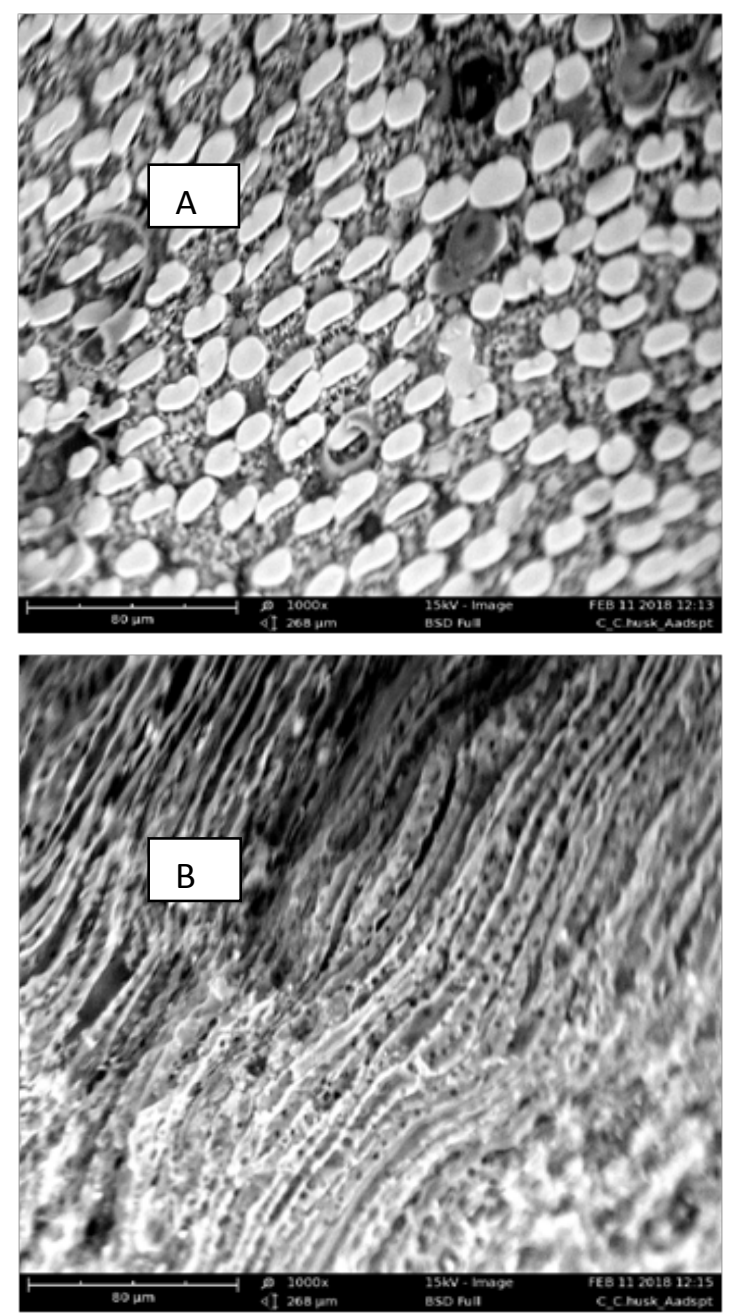

Figure 7 Carbonized Corn Husk (A) before adsorption and (B) after adsorption.

\section{Conclusion}

This study showed that the three adsorbents used (Rice husk, millet husk and corn husk) are promising adsorbents for the removal of nickel, chromium and manganese ions from aqueous solution. Initial metal ion concentration, adsorbent dosage, contact time, rate of agitation and $\mathrm{pH}$ as factors that affect adsorption process of metal were studied using aqueous solution. The maximum uptake of all the three metals occurred at constant time of $20 \mathrm{~min}$., agitation rate of $200 \mathrm{rpm}$, adsorbent dosage of $0.2 \mathrm{~g}$ and metal ion concentration of $0.6 \mathrm{mg} / 1$. Pai sample test was used to determine the efficiency of the biosorbents on the removal of the Chromium, Nickel and Manganese. It can be observed that, all the three adsorbents were good for the removal of heavy metal ions in aqueous solution. The development of these adsorbents for the treatment of effluents from Industries and domestic wastes is therefore recommended. This will reduce the harmful effect of residual metal ions found in ground water, soil-sediments water ways and many other sources.

\section{Acknowledgments}

None.

\section{Conflicts of interests}

The authors declare that there is no conflict of interests.

\section{References}

1. Volesky B, Holan ZR. Biosorption of heavy metals. Biotechnol Prog $1995 ; 11(3) ; 235-250$

2. Gavrilescu M. Removal of heavy metals from the environment by biosorption. Engr In life Sci. 2004;4(3):219-232.

3. World Health Organization. Lead environmental health criteria. Geneva 1995

4. Quek SY, Wase DAJ, Forster CF. The use of sago waste for the sorption of lead and coper. Water Sci Technol. 1998;24(3):251-256.

5. Paknikar AB, Ballester A, Gonzalez F, et al. Study of cadmium biosorption by orange wastes using the subsequent addition method. Bioresour Technol. 2008;99(17):8101-8106.

6. Kim SD, Park KS, Gu MB. Toxicity of hexavalent chromium to Daphnia magna: influence of reduction reaction by ferrous iron. $J$ Hazard Mater. 2002;93(2):155-164.

7. Annadurai G, Juang RS, Lee DJ. Use of cellulose wastes for adsorption of dyes from aqueous solutions. Jour Hazard Mater. 2002;92(3):263-274.

8. Ingwe JC, Mbonu OF, Abia AA. Sorption kinetic interparticle diffusion and equilibrium partitioning of azo dyes on great millet (andropogon sorghum, waste biomass. Journal of Applied Sciences. 2007;7(19):2840 2847

9. Nguyen TAH, Ngo HH, Guo WS, et al. Applicability of Agricultural Waste and by product for Adsorptive Removal of Heavy Metals from Waste Water. (Review). Bioresour Technol. 2013;148:574-585.

10. Uche OAO, Ahmed JA. Effect of millet husk ash on index properties of marginal leteritic soil. Research Journal in Engineering and Applied Sciences. 2012;2(5):365-69.

11. Rudre AG, Nataray, Manamohan R. Finger millet ragi husk as a low cos adsorbent for removal of $\mathrm{Cu}$ (II) from electroplating effluent. Proceedings of International Conference on Advocates in Architecture and Civi Engineering (AARCV 2012), $21^{\text {st }}-23^{\text {rd }}$ June; 2012:414-418. ISBN $978-$ 93-82338-01-7.

12. Manju Chaudhay. Use of millet husk as a biosorbent for the removal of chromium and manganese ion from the aqueous solutions. Int Jon of Chemical Environmental and Pharmaceutical Research. 2011;2(1):3033.

13. Guilbert GE, Salgado DR, Rangel VNA, et al. Modification of rice husk to improve the interface in isolactic polypropylene composites. Latin American Applied Research. 2012;42(1):83-87.

14. Chigondo F, Ngumunda BC, Sithole SC, et al. Removal of laed (II) and copper (III) ions from aqueous solution by baobub (adomonsia digitata) fruit shells biomas. IOSR Journal of Applied Chemistry (IOSR - JAC). 2013;6(1):43-50.

15. Garg S, Weixing SS. Sunflower stalk as adsorbents for the removal of metal ions from waste water. Ind Eng Chem Res. 2008;37(4):1324-328. 
16. Ibrahim SC, Hanafiah MAKM, Yahya MZA. Removal of Cadmium from Aqueous Solution by Adsorption onto Sugarcane Bagasse. American eurasiaj. Agric \& Environs Sci. 2006;1(3):179-184.

17. Wang J, Chen C. Research advances in heavy metal removal by biosorption. Acta Sci Circumstantiae. 2010;30(4):673-701.

18. Lawal AO, Batagarawa SM, Oyeyinka OD, et al. Estimation of heavy metals in neem tree leaves along Katsina-DutsinMa-Funtua Highway in Katsina State. J Appl Sci Environ Manage. 2011;15(2):327-330.

19. Sears GW. Determination of specific surface area of colloidal silica by titration with sodium hydroxide. Anal Chem. 1956;28(12):1981-1983.

20. Okeiman FE, Onyenkpa VU. Binding of Cadmium, Copper, Lead and Nickelions with Melon (Citrullius Vulgari's) feed husk. Biol Waste. 2000;29:11-16.

21. Rafeah W, Zainab N, Veronica V. Removal of Mercury, Lead and Copper from aqueous solution by activated Carbon of Palm Oil empty fruit Bunch. World Appl Sci J. 2009;5:84-91.

22. Olayinka KO, Alabi Adu T. Sorption of Heavy metals from electroplating effluents by low-cost adsorbents (II): use of coconut shell and coconut husk. J Appl Sci. 2007;7(16):2307-2313.

23. Dakiky M, Khamis M, Manassara A, et al. Selective adsorption of chromium (VI) in industrial waste water using low-cost abundantly available adsorbents. Adv Environ Res. 2002;6(4):533-540.
24. Saeed A, Ighal M, Akhutar Mrd. Removal and recovery of lead (II) from single and multi metal $(\mathrm{Cd}, \mathrm{Cu}, \mathrm{Ni}, \mathrm{Zn})$ solutions by crop milling waste. (Black Corn Husk). J Hazard Mater. 2005;117(1):65-73.

25. Abdel-Ghani NT, Hefny M, EL-Chaghalby GA, et al. Removal of lead from aqueous solution using low-cost abundantly available adsorbent. Int J Environ Sci Technol. 2007;4(1):67-73.

26. Abdel-Ghani NT, El-Nashar RM, El-Chaghalby GA. Removal of Cr(III) and $\mathrm{Pb}(\mathrm{II})$ from solution by adsorption onto casuarina glauna tree leaves. Electronic J Environ Agric Food Chem. 2007;7(7):3126-3133.

27. Abdel-Ghani NT, El-Chaghalby GA. Simultaneous removal of chromium, copper, cadmium and lead from aqueous solution by adsorption onto Kaolin. Int J Geotechnics Environs. 2009;1(2);161-171.

28. Gupta VK, Guptam, Sharma SC. Process development for the removal of lead and chromium from aqueous solution using red mud, an aluminum industry waste. Water Res. 2001;35(5);1125-1134.

29. Aghozu IE, Emoruwa FO. Batch adsorption of heavy metals $(\mathrm{Cu}, \mathrm{Pb}, \mathrm{Fe}$, $\mathrm{Cr}$ and $\mathrm{Cd}$ ) from aqueous solutions, using coconut husk. A fr $J$ Environ Techno. 2014;8(4):239-246. 